\title{
Damage Assessment of Concrete Structures exposed to Fire
}

\author{
Emmanuel ANNEREL \\ Dr. ir.-arch. \\ Ghent University, \\ Faculty of Engineering \& \\ Architecture \\ Department of Structural \\ Engineering, \\ Magnel Laboratory for \\ Concrete Research \\ Ghent, Belgium \\ emmanuel.annerel@ugent.be
}

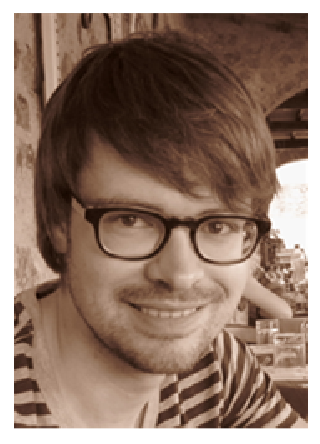

\author{
Luc TAERWE \\ Prof. dr. ir. \\ Ghent University, \\ Faculty of Engineering \& \\ Architecture \\ Department of Structural \\ Engineering, \\ Magnel Laboratory for \\ Concrete Research \\ Ghent, Belgium \\ luc.taerwe@ugent.be
}

\section{Summary}

During a fire, concrete structures behave in most cases very well. It could therefore be of economic interest to repair the damaged structures, as costs for demolition and rebuilding can be avoided and the building can be reused faster. To assess the remaining loadbearing capacity in a scientific based way, information is necessary about the temperature distribution inside the concrete element and the residual material properties of both concrete and steel. But, at least of equal importance is a fundamental insight in how a concrete structure could behave during a heating cycle, as indirect actions due to thermal restraints can occur and cause significant cracking. These effects should be noticed during a visual inspection of the structure, however, cracks introduced by internal thermal restraints are not visible from the concrete surface. In this paper, fundamental knowledge is given about the effect of heating and cooling on the compressive strength of concrete. Diagnosis tools are discussed to obtain the temperature distribution, especially in the neighborhood of the reinforcement. Those techniques are based on the physico-chemical transformations of the cement matrix and the aggregates that occur during heating. To determine the effect of thermal restraints on the structural behavior, a methodology based on finite element methods is illustrated.

Keywords: fire, concrete, performance based design, repair, assessment, FEM

\section{Introduction}

Durability of concrete structures is today an important social and environmental topic, as well as safety with respect to fire. Regarding fire, two options for insuring the durability are possible.

Firstly, the structure can be designed more adequate with respect to fire damage (i.e. performance based design). The concrete composition can be improved with polypropylene fibres, blended cement types or fire resistant aggregates. Also, more reinforcement can be provided at locations where severe damage is expected due to actions from thermal restraints or explosive spalling.

Secondly, the structure can be repaired after fire. Concrete structures behave in most cases very well. It could therefore not only be of social, but also of economic interest to repair the damaged structures, as costs for demolition and rebuilding can be avoided and the building can be reused faster.

This paper focuses mainly on repair of concrete structures after exposure to fire. Three aspects are investigated that provide the necessary and fundamental scientific knowledge to do a fire damage assessment in a systematic way. Firstly, techniques are developed to assess the temperature history of the exposed concrete elements. Secondly, experimental programmes are executed to model the loss of mechanical properties as function of temperature. And finally, the benefit of advanced 
calculation methods for estimating the remaining load bearing capacity of concrete structures is illustrated.

\section{Physico-chemical transformations}

Concrete is composed of aggregates that are embedded in a cement matrix that is composed of hydration products, such as ettringite, portlandite $(\mathrm{CH})$ and calcium silicate hydrates $(\mathrm{CSH})$. All these components are affected by the fire [1].

The dissociation process of the cement matrix is dominated by dehydration of the free and bound water, resulting in the breakdown of the ettringite at about $70^{\circ} \mathrm{C}$ and the portlandite beyond $450^{\circ} \mathrm{C}$. The $\mathrm{CSH}$ phases are more stable during fire, although they suffer from different transformations and disintegrate completely at about $800-900^{\circ} \mathrm{C}$. These dissociation processes yield additional pore space in the cement matrix.

Figure 1 shows magnifications of the interfacial zone of a concrete made with Portland cement, taken with an electron microscope. The image on the left shows unheated concrete, from which the hydration products can be observed. On the other hand, on the right, the concrete is heated to $550^{\circ} \mathrm{C}$ and therefore only the CSH is still present. An increase of the porosity is found as the number of black spots increases. These black spots correspond to the locations where the ettringite and portlandite used to be.
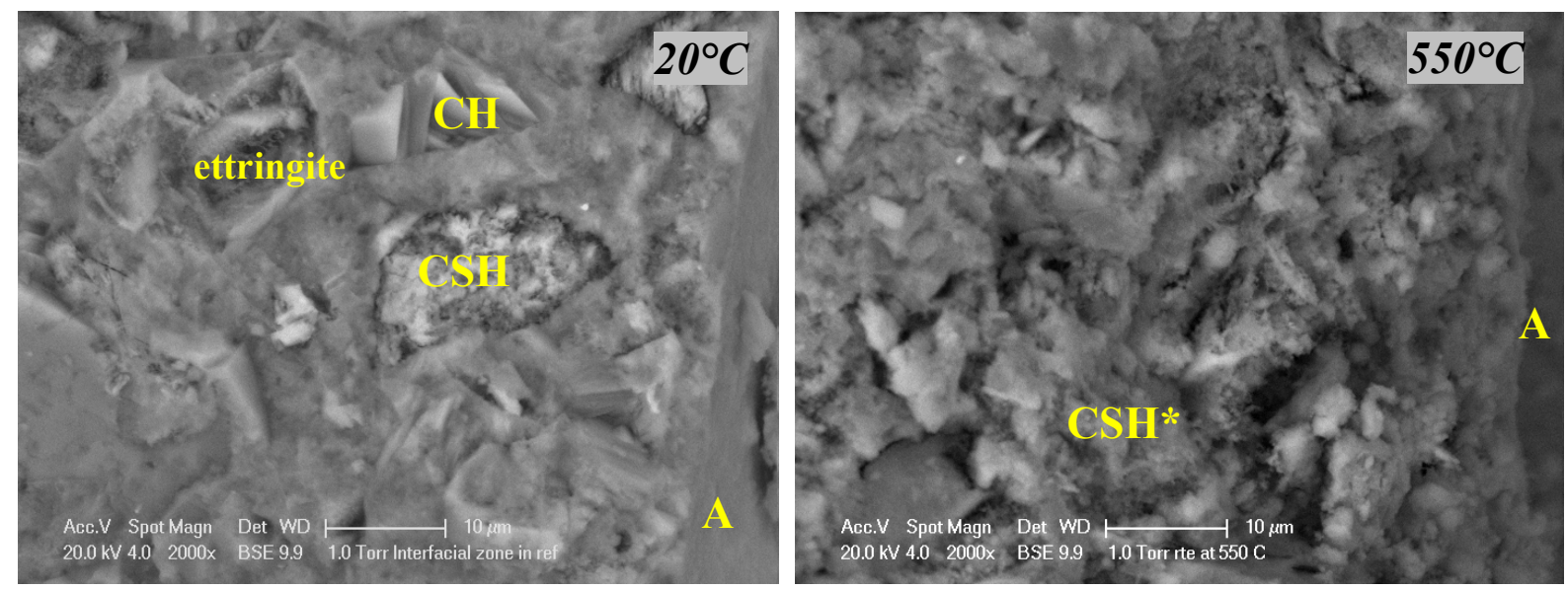

Fig. 1: Interfacial zone at ambient temperature and heated to $550^{\circ} \mathrm{C}(\mathrm{CH}=$ portlandite, $\mathrm{CSH}=$ calcium silicate hydrates, $\mathrm{CSH}^{*}=\mathrm{CSH}$ altered by fire, $A=$ aggregate) [1].

Also, the aggregates suffer from damage due to fire. Siliceous aggregates colour red due to oxidation of the iron oxides at $300-350^{\circ} \mathrm{C}$, while at $573^{\circ} \mathrm{C}$ quartz experiences an endothermic crystalline $\alpha-\beta$ phase transformation. Calcareous aggregates have better fire resistance with stability up to $700^{\circ} \mathrm{C}$, where they lose strength due to decarbonation.

After fire, hydration is possible of the unhydrated cement particles that are now accessible for moisture due to the increased porosity. This process can result in limited strength recovery. More important is the portlandite formed out of the chemical reaction of the available calcium oxide with water, as this reaction is expansive and leads to additional strength loss during the first weeks after fire. 


\section{Cracks in concrete induced by fire}

When a concrete structure is exposed to fire, different types of cracks may develop:

- $\quad$ Around the perimeter of the aggregates, cracks develop due to the difference in thermal expansion of the aggregates and the cement matrix.

- $\quad$ Both the concrete and reinforcement suffer from a loss of strength and stiffness during heating at high temperatures, which causes a loss of load bearing capacity. This loss can result in important cracking of the structure.

- Due to the low conductivity of concrete, a thermal gradient exists over the thickness of a concrete element. As a result, the outer concrete layers expand more than the inner layers. Therefore, the inner layers will restrain the expansion of the outer layers, which will result in cracks in the concrete mass that are not visible from the concrete surface. Such a crack pattern can be a pitfall when assessing the remaining load bearing capacity.

- $\quad$ Concrete elements are exposed to indirect actions, such as axial forces and moments, when their deformation is restraint by other parts of the structure. Because of this restraint, structural cracks can be developed.

- The connections between concrete elements are also affected by the indirect actions caused by restraint thermal expansion and can lead to cracking.

- Similar actions occur in the cooling phase, which can lead to additional cracking.

Information about cracking is of importance for a performance based design, as well as the repair after fire. Therefore, it is important to consider the described effects in the design stage and in the assessment after fire. A method based on finite element analysis may be necessary.

\section{Assessment techniques}

Different techniques are studied to evaluate the strength loss of concrete after fire $[1,2,3]$. These techniques may have a direct relationship with a mechanical property (UPV and Schmidt Rebound Hammer) and/ or are studied in respect to the reached temperature (porosity, colour and petrography). Strength loss can then be found from the degradation curves as function of temperature.

The first group of techniques can be used in a non-destructive way, providing additional information to a visual inspection. They are used to scan the highly damaged outer layers of the concrete for surface hardness. From the identified damaged zones, cores can be drilled for further investigation in the laboratory. Based on the test results of the Schmidt Rebound Hammer, a decay of surface hardness to $85 \%$ of the initial value is proposed as onset of fire damage for siliceous concrete.

The increase of porosity with temperature is studied with a flatbed scanner. This method is sensitive to the scanner settings and interpretation of the researcher. A very cheap and more objective technique is measuring the water absorption after immersion of the specimens under water [3]. A water immersion test is executed according to NBN B15-215 which is a standard test for determining the internal transport properties of concrete at ambient temperature. A database is available in the laboratory consisting of test results for a large number of concrete types. Since differences are found depending on the concrete composition, calibration of the porosity values by means of heating of in situ drilled specimens may be necessary. Generally, an increase of the water absorption above about 5\% is indicated as the beginning of damage due to fire.

The colour change can be measured with a spectrophotometer. This device records the colour in a device independent way and is easy to use in both laboratory and in situ explorations. With 
increasing temperature a colour path is found in the CIE Lab colour space that is shaped like an ellipse $[2,3]$. Figure 2 illustrates these colour paths for traditional and self-compacting concrete.

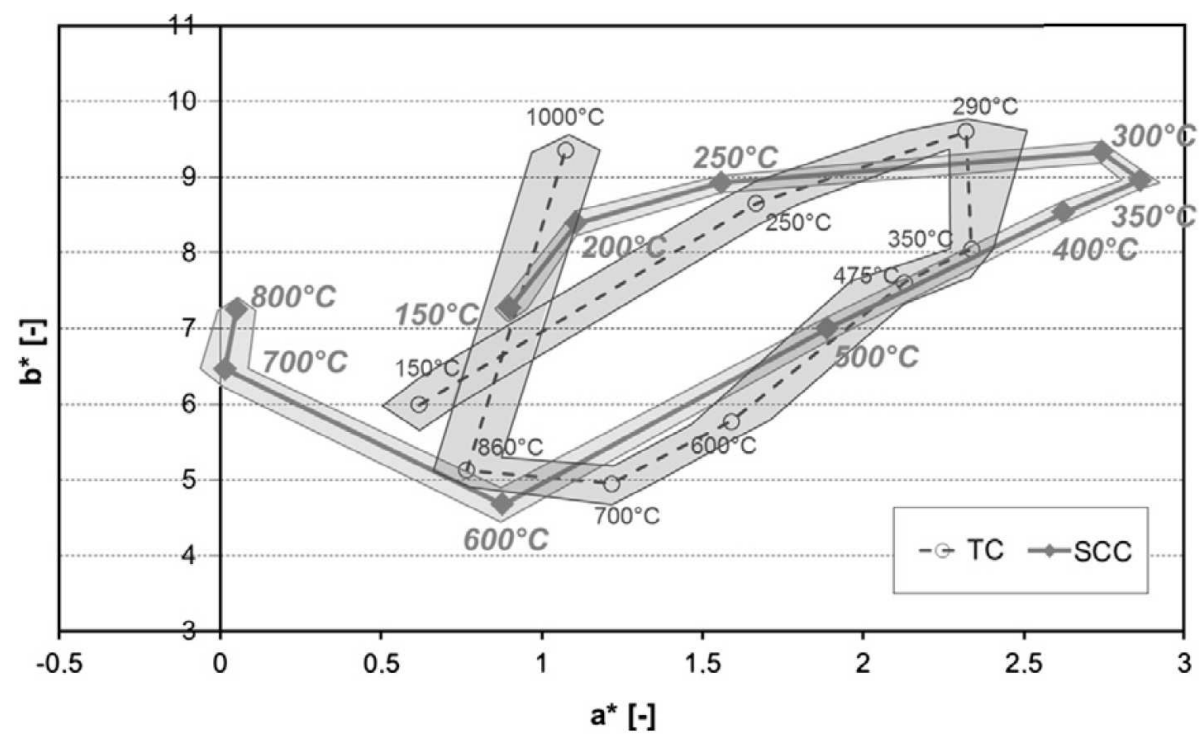

Fig. 2: Colour paths as function of temperature of polished samples of traditional concrete (TC) and self-compacting concrete (SCC) [2].

The colour of the cement matrix changes from grey at ambient temperature to red between 300 $600^{\circ} \mathrm{C}$, whitish grey around $600-900^{\circ} \mathrm{C}$ and buff at $900-1000^{\circ} \mathrm{C}$. The colour of the aggregates also changes with temperature. However, a distinction is found between siliceous and calcareous aggregates. Siliceous aggregates have a wide spread of colours at ambient temperature. When heated, they may follow different colour paths depending on their composition. However, most of them turn pink with increasing temperature due to the oxidation of the present iron oxides. On the other hand, the studied calcareous aggregates are coloured black at ambient temperature and change only visibly at about $700^{\circ} \mathrm{C}$ where they turn whitish due to decarbonation. To minimise the colour spread, the aggregates are blackened before measurement.

Petrography is interesting, because the different physico-chemical transformations are directly visible, allowing to identify the location of the different isotherms. By means of a stereomicroscope already different features can be detected. If necessary, more detailed information can be found when studying thin sections under a polarising and fluorescent microscope or by using an electron microscope [1].

\section{Residual material properties}

A second aspect deals with the degradation of the mechanical properties of concrete after fire. Different parameters influence the remaining compressive strength of concrete.

Concerning the composition of the concrete, fire resistant aggregates and the use of blended cements are recommended. The addition of pozzolanic materials enhances the fire resistance, because the amount of portlandite is replaced during the hydration process by more thermally stable phases. Generally, a strength loss is found at about $100^{\circ} \mathrm{C}$, after which the strength recovers at about $200^{\circ} \mathrm{C}$. However, beyond $300^{\circ} \mathrm{C}$ the strength decreases due to further disintegration processes of the cement matrix and the aggregates.

Most important influencing factors are the rate of cooling, the way and duration of post-cooling storage and the existence of external load. Rapid cooling by means of water immersion results in 
additional cracking and thus strength loss due to a thermal shock. Strength losses of up to 30-35\% are found in the experimental work. Because of the further deterioration process during cooling and subsequent storage, the strength is reduced further the first weeks after fire. Strength losses of 15$30 \%$ are found during the first 7-21 days after heating. Afterwards, the strength may recover which occurs at a faster rate when stored in water. However, this recovery is limited compared to a full recovery as stated in the literature.

Further, the application of load during heating introduces an additional strain type in the concrete, called transient strain. Depending on the load ratio, smaller strength losses are observed, corresponding to smaller strain levels. A constitutive strain model for the behaviour during heating [4] and a full post-cooling stress-strain model based on the Sargin model given in EN 1992-1-1 [5] are derived, taking into account temperature, load level and in the latter case also the post-cooling storage in air. Figure 3 shows the adapted Sargin models for a traditional concrete, uniformly heated to $20,175,300$ and $520^{\circ} \mathrm{C}$ and submitted during heating to different load levels, namely 0,20 and $30 \%$ of the initial strength.

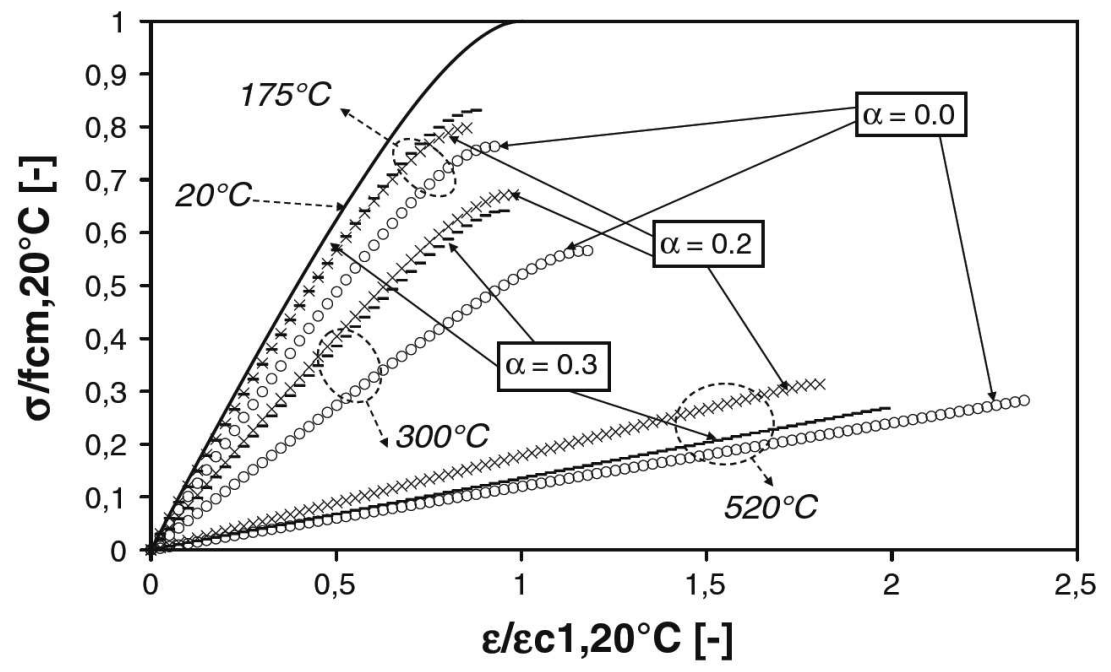

Fig. 3: Stress-strain model for a traditional concrete, heated under load and after 7 weeks of postcooling storage [5].

\section{Remaining load bearing capacity}

A final aspect concerns methods that can be used to calculate the load bearing capacity of individual members after fire exposure.

The remaining load bearing capacity of a small pretensioned beam exposed to a natural fire with an intensity corresponding to the ISO 834 curve is studied [6]. After the fire, the beam is tested for bending at Magnel Laboratory for Concrete Research. Specimens are taken from the beam to obtain both the residual concrete and reinforcement properties. Adequate agreement is found with the experimental value when calculating the remaining load bearing capacity with the techniques given in EN 1992-1-1 and by taking into account the measured mechanical properties after fire of both concrete and reinforcement. However, a simplified calculation method $\left(500^{\circ} \mathrm{C}\right.$ isotherm according to EN 1992-1-2) results also in sufficient agreement with the experimental data. This research has been further extended on other slabs and beams submitted to the ISO 834 curve. From this study, it seems that the remaining capacity can be best approached by using a $450^{\circ} \mathrm{C}$ isotherm instead of the $500^{\circ} \mathrm{C}$. 
It is noticed that the choice of the used calculation method has an influence on the amount of information needed about the temperatures reached inside the concrete, as well as the required information about the remaining concrete strength. When using the $500^{\circ} \mathrm{C}$ isotherm method, for instance, only the temperature of the reinforcement and the location of the $500^{\circ} \mathrm{C}$ isotherm should be assessed. The location of this isotherm can for instance be determined with an optical microscope, since at $450-550^{\circ} \mathrm{C}$ the portlandite is disappeared and at $573^{\circ} \mathrm{C}$ radial cracking of siliceous aggregates is observed. Furthermore, this method takes only into account the initial concrete strength, which is easier than assessing the additional strength losses upon heating, cooling and post-cooling storage. However, more information about the decreased concrete strength and the temperature history is needed when using calculation methods based on more isotherms, as is the case for a refined cross sectional analysis or complex finite element analysis.

Moreover, it is of importance to consider the global structural behaviour and thus the influence of restraint thermal actions. As discussed above, these restraints may induce cracking at the connections of the individual elements or in the concrete mass, not visible from the exterior. Such cracking can lead to failure of the structure before the fire resistance as calculated according to EN 1992-1-2 is attained, for instance shear failure at column tops. Therefore, it is of importance to study the global structural fire response for both design and assessment after fire. The internal cracks should be located and filled with e.g. an epoxy resin to regain stiffness capacity.

The effect of thermal restraints on the load bearing capacity can be modelled with the method of finite elements by introducing the developed material models. This approach can help to indicate the locations of the hidden cracks. Figure 4 shows, by way of example, the results of a thermomechanical calculation with the software package Diana of a typical column-beam connection submitted to 57 minutes of ISO 834 fire. The development of cracks is visible on the left, whereas the reinforcement stresses are given on the right. The thickness of the cracks is between $0.1-4 \mathrm{~mm}$, while the most of them are between 0.1 and $0.5 \mathrm{~mm}$. Notice the existence of bending cracks that do not extend towards the concrete surface. This behaviour is due to compressive stresses near the concrete surface induced by internal restraint of the upper, colder concrete layers. At this stage of the fire, the column reinforcement reaches the yielding limit.

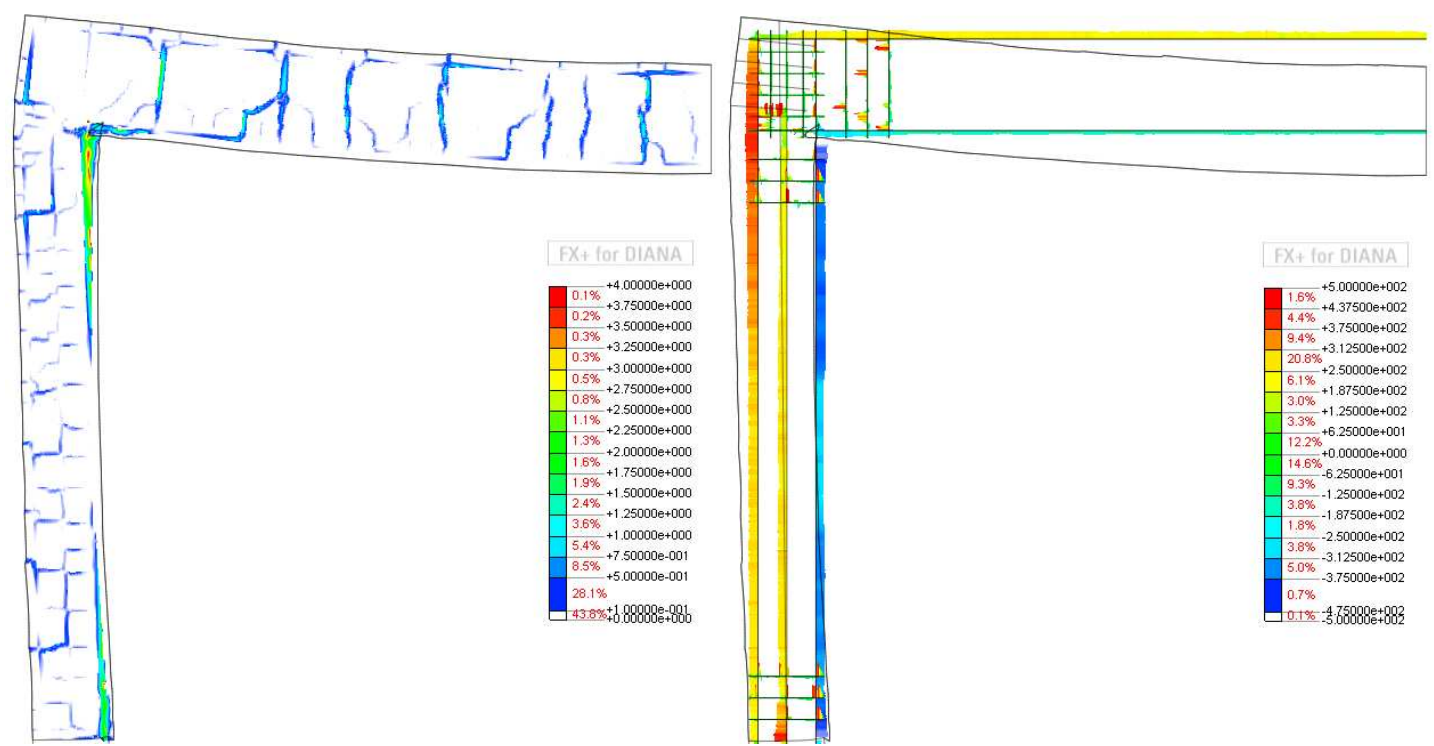

Fig. 4: Behavior of a column-beam connection after 57 minutes ISO 834 fire: principal cracking (left) and reinforcement stresses (right). 
Figure 5 shows the behavior of the structure after 58.5 minutes of fire exposure. A large crack appears in the left corner at the connection between the beam and column. This crack has a width of $2.5 \mathrm{~mm}$ and enlarges to about $7 \mathrm{~mm}$ afterwards. Due to this crack, a redistribution of the forces occur and the reinforcement stresses are reduced.

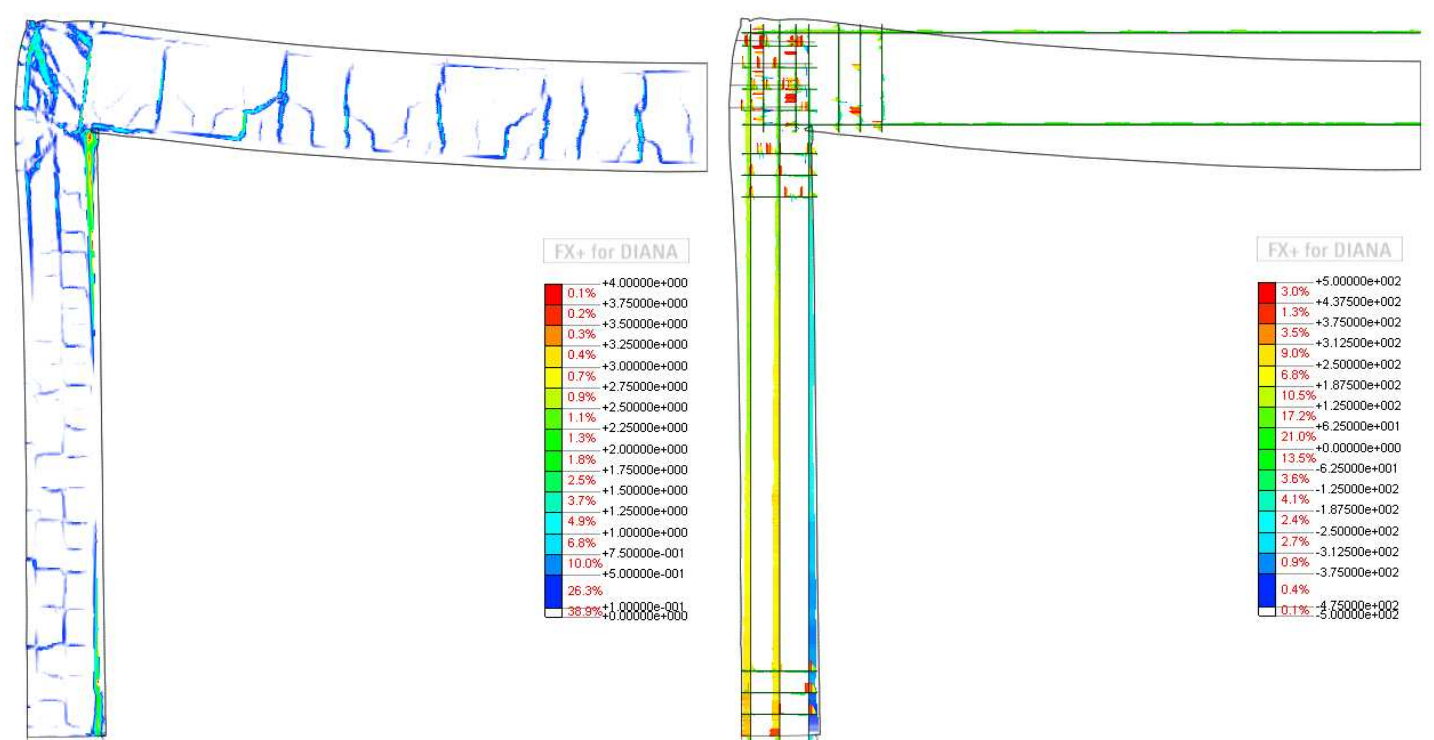

Fig. 5: Behavior of a column-beam connection after 58.5 minutes ISO 834 fire: principal cracking (left) and reinforcement stresses (right).

\section{Conclusions}

- Assessment techniques are developed to reveal the temperature history of concrete structures exposed to fire.

- Material models are developed to calculate the remaining compressive strength as function of load, temperature and effects of post-cooling storage.

- Finite element analysis can help to locate the zones with internal cracking due to thermal restraints.

- $\quad$ Finite element analysis can help to study the global structural behavior of a concrete structure exposed to fire, taking into account the redistribution of forces caused by thermal restraints.

\section{Acknowledgement}

The authors would like to thank the Fund for Scientific Research in Flanders (FWO) for the financial support through the research grant "Damage Assessment and Estimation of the Residual Strength of Concrete Members after Exposure to Fire", as well as IWT Flanders through the research grant "Development of a methodology for diagnosis and repair of concrete structures exposed to fire".

\section{References}

[1] ANNEREL E., TAERWE L., "Revealing the temperature history in concrete after fire exposure by microscopic analysis", Cement and Concrete Research, Vol. 39, No. 12, 2009, pp. 1239-1249. 
[2] ANNEREL E., TAERWE L., "Methods to quantify the colour development of concrete exposed to fire", Construction and Building Materials, Vol. 25, 2011, pp. 3989-3997.

[3] ANNEREL E., TAERWE L., "Basic Approach for the Diagnosis of Concrete after Fire Exposure", Journal of Structural Fire Engineering, Vol. 1, No. 3, 2010, pp. 135-143.

[4] ANNEREL E., TAERWE L., "Strain model for traditional and self-compacting concrete during fire", Fire and Materials, 2012, published online: DOI 10.1002/fam.2126

[5] ANNEREL E., TAERWE L., "Evolution of the strains of traditional and self-compacting concrete during and after fire", Materials and Structures, Vol. 44, 2011, pp. 1369-1380.

[6] ANNEREL E., TAERWE L., "Load bearing capacity of precast concrete elements after fire", Proceedings of the 1st International Workshop on Concrete Spalling due to Fire ExposureFrom real life experiences and practical applications to lab-scale investigations and numerical modelling, Leipzig (Germany), 3-5 September 2009, ed. F. Dehn and E.A.B. Koenders, pp. 41-51. 